\title{
In vivo antitumoural activity and composition of an oil extract of Brazilian propolis
}

\author{
Adriana Andrade Carvalho ${ }^{\mathrm{a}}$, Daiane Finger ${ }^{\mathrm{b}}$, Christiane Schinieder Machado ${ }^{\mathrm{b}}$, Eduardo Morgado Schmidt ${ }^{\mathrm{b}}$, \\ Patrícia Marçal da Costa ${ }^{\mathrm{a}}$, Ana Paula Negreiros Nunes Alves ${ }^{c}$, Thamires Maria Fontenele Morais ${ }^{\mathrm{d}}$, \\ Maria Goretti Rodrigues de Queiroz ${ }^{\mathrm{d}}$, Sueli Pércio Quináia ${ }^{\mathrm{b}}$, Marcos Roberto da Rosa ${ }^{\mathrm{b}}$, \\ Julio Murilo Trevas dos Santos ${ }^{\mathrm{b}}$, Cláudia Pessoa a ${ }^{\mathrm{a}}$, Manoel Odorico de Moraes ${ }^{\mathrm{a}}$, Letícia Veras Costa-Lotufo ${ }^{\mathrm{a}}$, \\ Alexandra Christine Helena Frankland Sawaya ${ }^{\mathrm{e}}$, Marcos Nogueira Eberlin ${ }^{\mathrm{f}}$, Yohandra Reyes Torres ${ }^{\mathrm{b}, *}$ \\ a Departamento de Fisiologia, Universidade Federal do Ceará, Fortaleza, CE, Brazil \\ ${ }^{\mathrm{b}}$ Departamento de Química, Universidade Estadual do Centro-Oeste, Guarapuava, PR, Brazil \\ ${ }^{\mathrm{c}}$ Departamento de Clínica Odontológica, Universidade Federal do Ceará, Fortaleza, CE, Brazil \\ ${ }^{\mathrm{d}}$ Faculdade de Farmácia, Universidade Federal do Ceará, Fortaleza, CE, Brazil \\ e Departamento de Fisiologia Vegetal, Instituto de Biologia, Universidade Estadual de Campinas, Campinas, SP, Brazil \\ ${ }_{\mathrm{f}}^{\mathrm{f}}$ Laboratório ThoMSon de Espectrometria de Massas, Instituto de Química, Universidade Estadual de Campinas, Campinas, SP, Brazil
}

\section{A R T I C L E I N F O}

\section{Article history:}

Received 2 June 2010

Received in revised form 16 November 2010

Accepted 6 December 2010

Available online 10 December 2010

\section{Keywords:}

Propolis

Edible oil extract

Antitumour activity

Phenolic compounds

\begin{abstract}
A B S T R A C T
The present study aimed to evaluate in vivo and in vitro the antitumoural activity of a propolis extract obtained with edible vegetable oil and its fractions and also to investigate its chemical composition by LC-MS and LC-MS/MS. To evaluate the toxicological aspects related to the propolis extract treatment, hematological, biochemical, histopathological and morphological analyses of treated animals were performed. All propolis extracts showed an in vivo antitumour activity in the experimental model with a moderate toxicity effect at experimental exposure levels. The oil extract was as effective as the ethanolic extract at inhibiting tumour growth. In vitro assays showed that the whole oil extract produced better inhibition of tumour cells than its fractions. LC-MS and LC-MS/MS identified four phenolic acids and three flavonoids. The anticancer potential of the oil extract of propolis has been demonstrated and the edible vegetable oil was shown as an attractive alternative solvent to extract bioactive natural propolis components.
\end{abstract}

(c) 2010 Elsevier Ltd. All rights reserved.

\section{Introduction}

The use of propolis is ancient in traditional medicine dating back at least to $300 \mathrm{BC}$ (Ghisalberti, 1979). Today, this resinous bee product continues to be used worldwide, and a broad spectrum of biological activities for propolis has been reported, including anticancer, antioxidant, anti-inflammatory, antibiotic, and antifungal activities (Burdok, 1998; Marcucci, 1995). The biological effect of propolis is attributed to its natural bioactive chemicals, such as polyphenols, flavonoid aglycones, phenolic acid and their esters, caffeic acid and their esters and phenolic aldehydes and ketones (Oršlic \& Basic, 2003).

Recently, attention is being focused on the anti-cancer activity of propolis. The studies, however, have been performed using ethanolic or hydroalcoholic extracts (Oršlic \& Basic, 2003). Ethanolic formulations of propolis prevent its consumption by people who

\footnotetext{
* Corresponding author. Address: UNICENTRO CEDETEG: Rua Simeão Camargo Varela de Sá, 03, Vila Carli - Guarapuava - PR, CEP 85040 080, Brazil. Tel.: +55 042 $36298324 / 8120$.

E-mail address: ryohandra@yahoo.com (Y.R. Torres).
}

can not consume alcohol for medical reasons, such as diabetic patients. Several patents have dealt therefore with new methods or solvents besides ethanol to extract propolis (Kasuma \& Kenichi, 2001a, 2001b; Namiki et al., 2005). These patents have reported the use of edible vegetable oils, triglycerides and fatty acids as extraction solvents for propolis. Data on the biological activity and chemical composition of oil extracts of propolis are, however, scarce. Tosi, Donini, Romagnoli, and Bruni (1996) evaluated the antimicrobial activity of commercial extracts of propolis prepared with different solvents including oils. They reported a wide range of antimicrobial activity for the oil extract and concluded that the solvent employed for the extraction of propolis influences the potency of its antimicrobial activity. We have compared antiproliferative activity against the HL-60, MDAMB-435 and SF-295 cells lines of oil and ethanolic propolis extracts (Buriol et al., 2009) and found out that oil extracts were active against the tumour cell line tested showing higher anticancer potential against the SF-295 cell line.

The aim of this study was to investigate the effects of the oil and ethanolic extracts of propolis in experimental models. Hematological, biochemical, histopathological and morphological analyses of the tumour and the organs, including liver, spleen and kidney, 
were performed to evaluate the toxicological aspects of the treatment. The results of this study should therefore advance the knowledge of the antitumour benefits of edible oil extracts of propolis and provide a better understanding of their application in the prevention/treatment of malignant tumours. Besides biological assays, the oil extract of propolis was also fractioned by chromatography and its fractions analysed using mass spectrometry to evaluate their chemical composition.

\section{Materials and methods}

\subsection{Propolis and extracts}

\subsubsection{Samples}

Propolis samples were collected in 2006 and supplied by Campolin and Schmidt Company from Prudentópolis city (Paraná State, Brazil). Propolis was stored at $-18^{\circ} \mathrm{C}$ until extraction.

\subsubsection{Extracts}

Fifty grams of propolis were extracted in a shaker with $500 \mathrm{ml}$ of canola oil or $70 \%$ ethanol, during $24 \mathrm{~h}$, at room temperature. After that period, the extractive solutions were filtered. The solvent was removed from the hydro-alcoholic solution yielding EEP70. The oil extract of propolis was partitioned into $80 \% \mathrm{v} / \mathrm{v}$ methanol/water and the aqueous methanolic phase was dried in a rotatory evaporator yielding ODEP.

\subsection{Chromatography fractionation}

Hundred and eighty milligrams of ODEP in methanol were applied on a glass column $(3 \times 80 \mathrm{~cm})$ containing Sephadex LH-20. The elution was performed with methanol. A total of 80 fractions of $8 \mathrm{ml}$ each were obtained. These fractions were joined in six new fractions, labeled as OLSx 1-6, through thin layer chromatography analyses on silica gel (mobile phase chloroform/acetone/acetic acid 18:4:1 v/v/v and visualisation of spots at UV of $254 \mathrm{~nm}$ with the use of $\mathrm{FeCl}_{3}$ as the colour reagent).

\subsection{Mass spectrometry analyses}

\subsubsection{ESI(-)-MS data}

Samples of OLSx 1-6 were analysed using a Q-Trap mass spectrometer (Applied Biosystems) with the direct infusion of the sample solutions into the electrospray ionisation source operating in the negative ion mode. Capillary and cone voltages were set to $-4500 \mathrm{~V}$ and $-50 \mathrm{~V}$, respectively, with a de-solvation temperature of $100^{\circ} \mathrm{C}$.

\subsubsection{Liquid chromatographic mass spectrometry analyses (LC-MS)}

OLSx 3-6 were introduced into an HPLC (Agillent) with a $\mu$ Bondapak C18 analytical column (Waters, 3,9 $\times 300 \mathrm{~mm}$, $10 \mu \mathrm{m}$ ) and detected in a Q-Trap mass analyser. ESI(-)-MS was carried out with capillary and cone voltages set to -4500 and $-50 \mathrm{~V}$, respectively, and a de-solvation temperature of $300{ }^{\circ} \mathrm{C}$. A binary mobile phase of acetonitrile and $1 \%$ of formic acid was employed. A linear gradient was performed starting from 30\% of acetonitrile to $100 \%$ acetonitrile, in $30 \mathrm{~min}$, and an elution flow rate of $1 \mathrm{ml} / \mathrm{min}$.

\subsection{3. $\operatorname{ESI}(-)-M S / M S$}

Tandem mass spectra were acquired using a hybrid high-resolution and high-accuracy ( $5 \mathrm{ppm}$ ) Micromass Q-TOF mass spectrometer (Waters) and via collision-induced dissociation at ca. $15 \mathrm{~V}$. Capillary and cone voltages were set to \pm 3000 and $\pm 40 \mathrm{~V}$, respectively, for the negative or positive mode of ionisation. The de-solvation temperature was $100^{\circ} \mathrm{C}$; nitrogen and argon were used as de-solvation or collision gas, respectively.

\subsection{Biological assays}

\subsubsection{Cytotoxicity assays}

The cytotoxicity of propolis extracts and fractions from ODEP was evaluated against four human tumour cell lines: HL-60 (leukemia), HCT-8 (colon), MDA/MB-435 (breast) and SF-295 (brain) obtained from the National Cancer Institute (Bethesda, MD, USA). The general viability of cultured cells was determined by the reduction of the yellow dye 3-(4,5-dimethyl-2-thiazolyl)-2,5-diphenyl-2H-tetrazolium bromide (MTT) to a blue formazan product, as previously described by Mosmann (1983).

The tumour cells were maintained in RPMI 1640 medium, supplemented with $10 \%$ fetal bovine serum, $1 \%$ penicillin and streptomycin at $37{ }^{\circ} \mathrm{C}$ with $5 \% \mathrm{CO}_{2}$. For all experiments cells were seeded at $0.3 \times 10^{6}$ cells $/ \mathrm{ml}$ (HL-60, MDA/MB-435 e SF-295) and $0.7 \times 10^{5}$ cells $/ \mathrm{ml}$ (HCT-8), and incubated during $72 \mathrm{~h}$ with propolis extracts $(0.001-50 \mu \mathrm{g} / \mathrm{ml}$ ODEP and EEP70) and fractions (0.001-25 $\mu \mathrm{g} / \mathrm{ml})$, under the conditions described above. After centrifugation and solution removing, MTT solution was added and the plates were incubated, centrifuged, and the solids dissolved in pure and sterile DMSO. The absorbance was measured in a plate spectrophotometer DTX-800 (Beckman Coulter) at $595 \mathrm{~nm}$. Doxorubicin (Sigma) was used as a positive control.

\subsubsection{In vivo antitumoural assays}

2.4.2.1. Animals. A total of 80 Swiss mice (male, $25-30 \mathrm{~g}$ ), obtained from the central animal house of Federal University of Ceará, Brazil, were used. The animals were housed in cages with free access to food and water (conforming to a well-defined rodent diet). All animals were kept under a 12:12 h light-dark cycle (lights on at 6:00 a.m.). The animals were treated according to the ethic principles of animal experimentation of COBEA (Colégio Brasileiro de Experimentação Animal), Brazil. The Animal Studies Committee of the Federal University of Ceará approved the experimental protocol.

Sarcoma 180 tumour cells were maintained in the peritoneal cavities of the Swiss mice obtained from the central animal house of the Federal University of Ceará.

2.4.2.2. Determination of the effect of propolis extract on tumour growth in vivo. Ten-day-old sarcoma 180 ascites tumour cells $\left(2 \pm 10^{6}\right.$ cell $\left./ 500 \mu \mathrm{l}\right)$ were implanted subcutaneously into the left hind groin of the experimental mice. One day after inoculation, the propolis extracts (50 and $80 \mathrm{mg} / \mathrm{kg}$ to ODEP and EEP70) or 5 -FU $(25 \mathrm{mg} / \mathrm{kg})$ were dissolved in $4 \%$ DMSO and administered intraperitoneally for 7 days. The negative control was injected with $4 \%$ DMSO. On day 8 th, the mice were killed and the tumours were excised, weighed and fixed in $10 \%$ formaldehyde. The inhibition ratio (\%) was calculated by the following formula: inhibition ratio $(\%)=[(A-B) / A] \times 100$, where $A$ is the average tumour weight of the negative control, and $B$ is the tumour weight of the treated group.

\subsubsection{Toxicological analysis}

2.4.3.1. Effects of propolis extracts on organ and body weight. Determination of the effect of propolis extracts on the organ body weights were measured at the beginning and at the end of the treatment and the animals were observed for signs of abnormalities throughout the study. The positions, shapes, sizes and colour of internal organs, namely kidneys, liver and spleen were observed for any signs of gross lesions. These organs were collected, weighed and fixed in $10 \%$ formaldehyde. 
2.4.3.2. Determination of the effect of propolis extract on biochemical parameters. After fasting for $6-8 \mathrm{~h}$, the animals were submitted to blood collection from the orbital plexus for biochemical analysis (urea and creatinine to investigate any renal function alterations; AST and ALT as liver parameter). The analysis was carried out in a semi-automatic equipment $\left(\right.$ LabQuest $\left.^{\circledR}\right)$, using enzymatic colourimetric kits, while the hematological cells were quantified in a Sysmex ${ }^{\circledR}$ KX-21 N. The methodology of the LabQuest and Sysmex equipment are based, respectively, on the principle of absorption and impedance.

2.4.3.3. Determination of the effect of propolis extracts on hematological parameters. After fasting for $6-8 \mathrm{~h}$, the animals were submitted to blood collection from the orbital plexus for hematological analyses. The hematological analyses were performed by an optical microscope Olympus ${ }^{\circledR}$ BX 41 . Hematological parameters, including the hemoglobin content, platelet count, total count of leukocytes as well as a differential count of leukocytes, such as eosinophil (\%), lymphocyte (\%), neutrophil (\%) and monocyte (\%) were measured.

\subsubsection{Histopathology and morphological observations. After being} fixed with formaldehyde, tumours, livers, spleens and kidneys were grossly examined for size or colour changes and hemorrhage. Subsequently, portions of the tumour, liver, spleen and kidney were cut into small pieces, followed by staining with hematoxylin and eosin of the histological sections. Histological analyses were performed by light microscopy. The occurrence and the extent of liver or kidney lesions attributed to drugs were recorded.

\section{Results}

\subsection{Analysis of ODEP chemical composition by ESI(-)-MS, LC-MS and $L C-M S / M S$}

ODEP fractionation gave fractions OLSx 1-6, which were first analysed by direct infusion ESI(-)-MS. Since propolis is a rich natural bee product containing mainly phenolic compounds, such as cinnamic acid derivatives and flavonoids, ions were mostly produced by electrospray ionisation in the negative ion mode. ESI(-) is a soft ionisation technique and mass spectra mainly detected components as their intact deprotonated molecules. ESI(-)-MS provides therefore fingerprinting characterisation of propolis extracts via characteristic profiles of their chemical composition in terms of the most polar and acidic or basic components (Sawaya et al., 2004a, 2007).

Fig. 1 shows the ESI(-)-MS fingerprints of ODEP fractions and indicates great differences in the chemical composition between the fractions. OLSx 1 and OLSx2 were complex fractions with several high to medium abundant ions, such as $m / z 387,311,341$ and 275 (OLSx1). For OLSx2, the highest abundant ions were those of $m / z 315,339$, with medium abundant ions of $m / z 265,325,293$ and 377. Fractions OLSx 3-6 were simpler and showed mostly a single major ion. OLSx3 showed mostly the ions of $m / z 247,231$, 301 and 393 whereas OLSx 4 showed those of $m / z$ 301, 245, 393 and 287 as most abundant. Fractions OLSx 5 and OLSx6 showed a major common ion of $\mathrm{m} / \mathrm{z} 299$ and other less abundant ions of $\mathrm{m} /$ $z 329$ and 387 (OLSx5) and $m / z$ 249, 285, 311 and 387 (OLSx6).

To characterise the fractions constituents, LC-MS and LC-MS/ MS were performed. Via comparisons with the fragmentation pattern of previously identified compounds (Marcucci, Sawaya, Custodio, Paulino, \& Eberlin, 2008), several components have been identified: 3,4-dihydroxi-5-prenyl-cinnamic acid ( $\mathrm{m} / \mathrm{z} 247$, OLSx3); dihydrokaempferide $(\mathrm{m} / \mathrm{z} 301$, OLSx3 and OLSx4); 3-prenyl-4hydroxicinnamic acid ( $m / z$ 231, OLSx3); (E)-3-\{-4-hydroxy-3-[(E)4-(2,3-dihydrocinnamoyl oxy)-3-methyl-2-butenyl]-5-prenylphe- nyl\}-2-propenoic acid $(\mathrm{m} / \mathrm{z} 447$, OLSx2). Isosakuranetin $(\mathrm{m} / \mathrm{z} 285$, OLSx4 and OLSx6) was identified by comparison of its MS/MS fragmentation with a standard kindly provided by Vassya S. Bankova, (Bulgarian Academy of Science). We have identified some of those compounds previously in the oil extracts of propolis (Buriol et al., 2009).

In addition, LC-MS identified two compounds with the same $m / z$ 299 but different retention time. Compound in OLSx2 with $[\mathrm{M}-\mathrm{H}]^{-}$ of $m / z 299$ and $t_{\mathrm{R}} 24$ min showed in its ESI(-)-MS/MS a fragmentation to the ion of $m / z 255$ via initial loss of 45 Da and of $m / z 244,200$ and 145. It was identified as 3,5-diprenyl-4-hydroxicinnamic acid also known by artepellin C. ESI(-)-MS/MS of the other compound with $[\mathrm{M}-\mathrm{H}]^{-}$of $m / z 299$ but $t_{\mathrm{R}} 14 \mathrm{~min}$ in OLSx5 and OLSx6 underwent fragmentation to the ion of $m / z 284$ via initial loss of a methyl radical and was identified as kaempferide. Other fragment ions of $m /$ $z 164,151$, and 107 are typical of the cleavage of the flavonoids central C-ring (Cuyckens \& Claeys, 2004) (Table 1).

\subsection{In vitro cytotoxicity assays}

Table 2 shows the results from the in vitro cytotoxic assays for the propolis extracts and the fractions obtained by the chromatographic separation of ODEP on Sephadex LH-20. The extract of propolis obtained with canola oil and dried (ODEP) displayed moderate cytotoxicity against leukemia (HL-60), melanoma (MDA-MB435) and glioblastoma (SF-295) cancer cells, a better result than the ethanolic extract (EEP70). When analysing cytotoxicity from ODEP fractions, it was evident that the fractions were less active than the propolis extract (ODEP) in the cell lines evaluated, whereas OLSx4 and OLSx 5 showed moderate cytotoxicity against leukemia (HL-60) and colon (HCT-8).

\subsection{Effect of propolis extracts on tumour growth in vivo and on organ and body weight}

To check if the cytotoxic effects observed in vitro also occured in vivo, we used the Sarcoma 180 (S-180) model which is a mouse-originated tumour frequently used in in vivo antitumour related research (Gonzaga et al., 2009). Fig. 2 shows the effects of the propolis extracts on mice transplanted with S-180 tumour. There was a significant reduction of the tumour weight in all extracts tested. The differences between experimental groups were compared by ANOVA followed by Student Newman Keuls or Bonferroni tests $(p<0.05)$. On the 8th day, the average tumour weight of the control mice inoculated with sarcoma 180 was $2.05 \pm 0.22 \mathrm{~g}$. In the presence of EEP70, the sarcoma 180 weight was reduced to $0.94 \pm 0.35$ and $0.90 \pm 0.22 \mathrm{~g}$ at doses of 50 and $80 \mathrm{mg} / \mathrm{kg}$, respectively. These reductions are equivalent to inhibition ratios of $53.94 \%$ and $56.29 \%$. In the presence of ODEP, the sarcoma 180 weight was reduced to $0.92 \pm 0.14$ and $0.96 \pm 0.24 \mathrm{~g}$ at doses of 50 and $80 \mathrm{mg} / \mathrm{kg}$, respectively. These reductions are equivalent to inhibition ratios of $54.94 \%$ and $53.35 \%$. At $25 \mathrm{mg} / \mathrm{kg}$, 5-FU reduced tumour weight by $51.56 \%$ within the same period. These results showed that the inhibition ratio of the ethanolic extract was the same as that of oil extract and no differences were observed when the extracts were tested at doses of 50 and $80 \mathrm{mg} / \mathrm{kg}$. It was demonstrated that both extracts of propolis inhibited the Sarcoma 180 tumour growth in mice.

After killing the animals, the organs were weighed. No significant changes in the organ weights were seen in any of the extract-treated animals (Fig. 2). After treatment with 5-FU, however, the spleen weights were significantly reduced when compared with the control group $(p<0.05)$. No significant gain in body weight was seen among the groups $(p>0.05)$ (data not shown). 


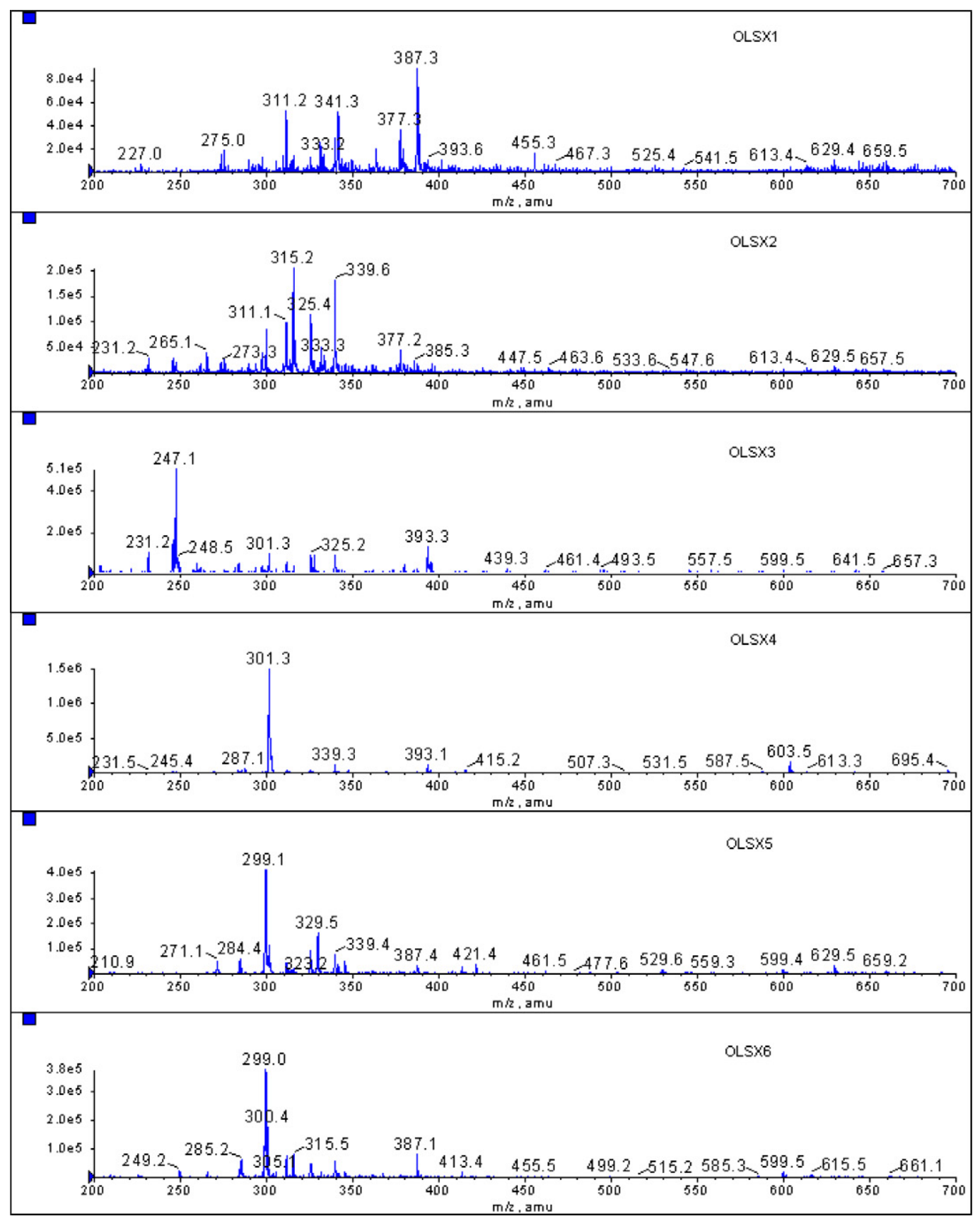

Fig. 1. ESI(-)-MS fingerprints from ODEP fractions.

Table 1

Identified compounds in fractions from the oil extract of propolis and ESI(-)-MS/MS fragments.

\begin{tabular}{|c|c|c|c|c|}
\hline Compound & Fraction & $t_{\mathrm{R}}$ & $m / z[\mathrm{M}-\mathrm{H}]^{-}$ & Main fragments: $m / z$ (relative abundance $\%$ ) \\
\hline 4-Hydroxy-3-prenylcinnamic acid & OLSx3 & 6,4 & 231 & 187 (50), $132(100)$ \\
\hline 3,4-Dihydroxy-5-prenylcinnamic acid & OLSx3 & 10,6 & 247 & 203 (100), 185 (10), $148(55)$ \\
\hline Isosakuranetin & $\begin{array}{l}\text { OLSx } 4 \\
\text { OLSx6 }\end{array}$ & 15 & 285 & 270 (10), 243 (20), 164 (100), 151 (20), 136 (20) \\
\hline Kaempferide & $\begin{array}{l}\text { OLSx5 } \\
\text { OLSx6 }\end{array}$ & 14 & 299 & 284 (100), 164 (10), $151(20)$ \\
\hline Artepillin C & OLSx2 & 24 & 299 & 255 (30), 200 (100), 185 (10), 145 (10) \\
\hline Dihydrokaempferide & $\begin{array}{l}\text { OLSx4 } \\
\text { OLSx3 }\end{array}$ & 10,8 & 301 & 283 (50), 227 (30), 152 (100), 151 (30), 125 (40), 107 (20) \\
\hline $\begin{array}{l}\text { (E)-3-\{-4-hydroxy-3-[(E)-4-(2,3-dihydrocinnamoyl oxy)- } \\
\text { 3-methyl-2-butenyl]-5-prenylphenyl\}-2-propenoic acid }\end{array}$ & OLSx2 & 20 & 447 & 297(100), 253 (10), 149 (90) \\
\hline
\end{tabular}


Table 2

In vitro cytotoxic activity of propolis extracts and fractions against tumour cell lines.

\begin{tabular}{lllll}
\hline Samples $(\mu \mathrm{g} / \mathrm{mL})$ & $\mathrm{IC}_{50}{ }^{\mathrm{a}}$ & & & \\
\cline { 2 - 5 } & $\mathrm{HL}-60$ & HCT-8 & MDA/MB-435 & SF-295 \\
\hline EEP-70 & $\mathbf{2 5 . 2 2}$ & $>40$ & $>40$ & $>40$ \\
ODEP & $25.67-33.72$ & & & \\
& $\mathbf{2 6 . 8 7}$ & $>40$ & $\mathbf{2 2 . 1 9}$ & $\mathbf{1 6 . 6 3}$ \\
OLSx1 & $23.27-31.02$ & & $12.10-40.68$ & $14.52-16.72$ \\
OLSx2 & $>25$ & $>25$ & $>25$ & $>25$ \\
OLSx3 & $>25$ & $>25$ & $>25$ & $>25$ \\
OLSx4 & $>25$ & $>25$ & $>25$ & $>25$ \\
& $\mathbf{2 4 . 1 2}$ & $\mathbf{2 2 . 3 2}$ & $>25$ & $>25$ \\
OLSx5 & $22.21-27.74$ & $20.10-24.14$ & & \\
OLSx6 & $\mathbf{2 3 . 1 5}$ & $\mathbf{1 8 . 1 2}$ & $>25$ & $>25$ \\
Doxorubicin & $21.14-25.34$ & $14.12-22.23$ & & \\
& $>25$ & $>25$ & $>25$ & $>25$ \\
& $\mathbf{0 , 0 2}$ & $\mathbf{0 , 0 1}$ & $\mathbf{0 , 4 8}$ & $\mathbf{0 , 2 4}$ \\
\hline
\end{tabular}

${ }^{a}$ Data are presented as $\mathrm{IC}_{50}$ values and $95 \%$ confidence interval obtained by nonlinear regression for leukemia (HL-60), colon (HCT-8), breast (MDA-MB-435) and brain (SF-295) cancer cells from two independent experiments performed four times $(n=8)$.

\subsection{Effect of the propolis extracts on biochemical parameters}

No significant changes in the renal (urea and creatinine levels) or liver [enzymatic activity of transaminases aspartate aminotransferase (AST) and alanine aminotransferase (ALT)] parameters were seen in the animals treated with propolis extracts (data compared by ANOVA followed by Student Newman Keuls or Bonferroni tests $p<0.05$ ) in mice transplanted with Sarcoma 180 tumour (Fig. 3). The animals treated with 5-FU have alteration on renal and liver parameters.

\subsection{Histopathology, morphological, and morphometric changes}

Histopathological analyses of the tumours extirpated from the control mice showed a malignant neoplasm composed of pleomorphic polygonal cells with little cytoplasm, some with vesicular nuclei, and acidophilic macronucleoli. Muscular invasion, areas of coagulation necrosis and typical and atypical mitotic figures were also observed. In the tumours extirpated from treated animals, extensive areas of coagulative necrosis were observed.
The histopathological analyses of livers, removed from all groups, showed foci of microvesicular steatosis. Mild swelling of hepatocytes and focal microvesicular steatosis were observed in the negative control group. In 5-FU-treated animals intense cell swelling of hepatocytes, microvesicular steatosis, hyperplasia of Kupffer cells and hemosiderin were observed. In ODEP-treated animals, moderate swelling cell hepatocyte, microvesicular steatosis, hyperplasia of Kupffer cells, inflammatory foci and bilirubin were observed. In EEP70-treated animals we found intense swelling of hepatocytes and large areas of microvesicular steatosis.

Analyses of the kidneys showed cilindrohialin, which indicates a difficulty of the renal filtration system of proteins. Severe swelling of the tubular epithelium was also found in all groups, including the 5-FU. All groups showed lymphoid follicles in the spleen, sometimes with large, irregular, ill-defined borders, probably related to the actual tumour (sarcoma 180) that leads to this histological finding. All groups showed areas of hemorrhage.

\subsection{Effect of the propolis extracts on hematological parameters}

The animals transplanted with Sarcoma 180 tumours treated with 5-FU showed a strong reduction on the total leukocytes $(p<0.05)$. Treatment with the propolis extracts demonstrated no alteration (Table 3 ).

\section{Discussions}

ESI(-)-MS, LC-MS and LC-MS/MS identified several prenylated phenolic acids and flavonoids in ODEP, demonstrating that vegetable oil was able to extract important bioactive natural phenolic compound from crude propolis. Compounds identified in the present work have been found in alcoholic and hydro-alcoholic extracts of propolis from Brazil and other countries and are related to many biological activities (Banskota, Tezuka, \& Kadota, 2001; Banskota et al., 1998; Lustosa, Galindo, Nunes, Randau, \& Neto, 2008; Sawaya, Souza, Marcucci, Cunha, \& Shimizu, 2004; Sawaya et al., 2002b). This is so for artepillin C, for instance, a major compound in green Brazilian propolis, for which biological activities, such as antimicrobial, antioxidant and anti-tumour, as well as increases in the immune response against leukemia have been reported (Shimizu, Ashida, Matsuura, \& Kanazawa, 2004). Because of these bio-

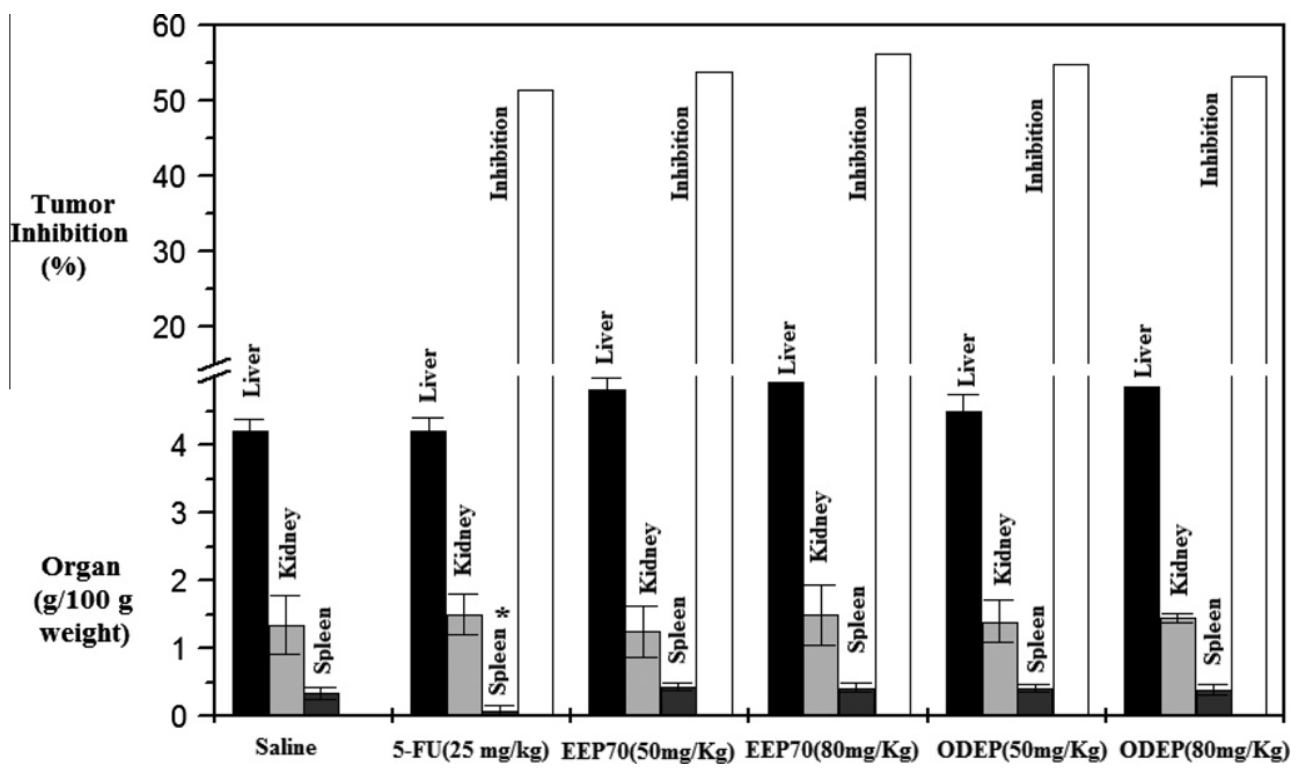

Fig. 2. Inhibition ratio on solid tumour and effect of propolis extracts on organ weights. 


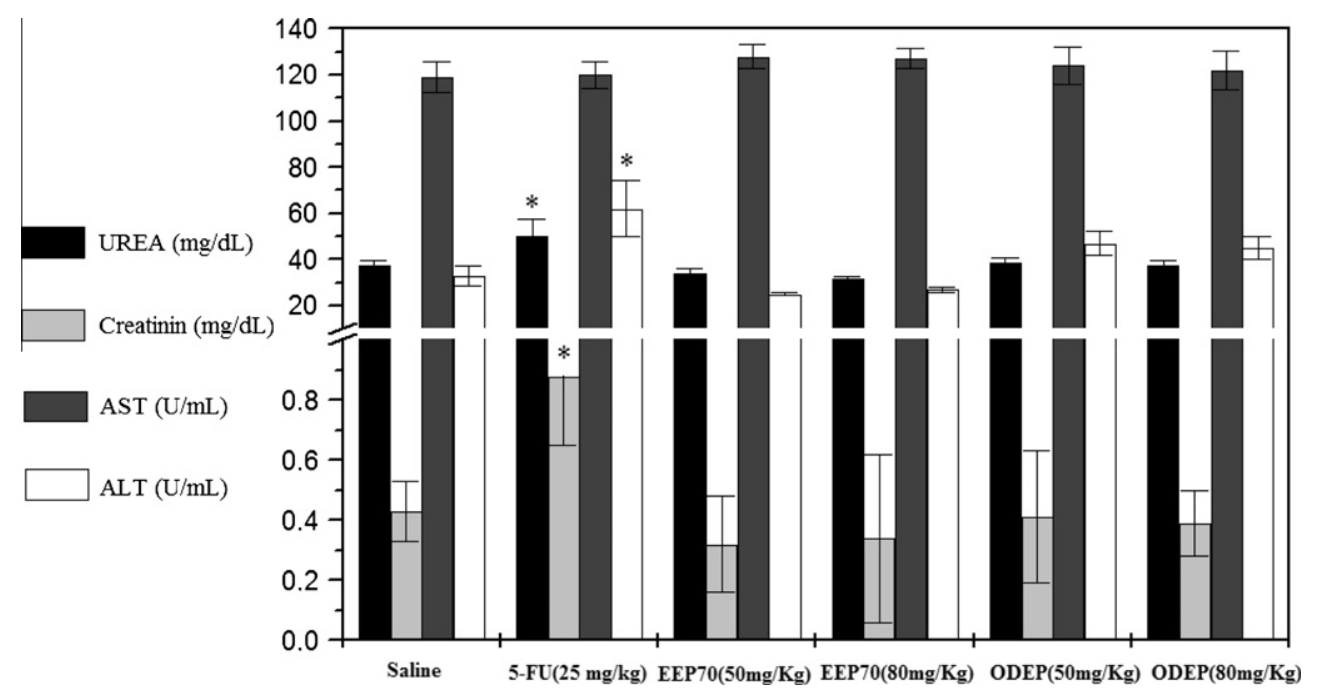

Fig. 3. Effect of propolis extracts on biochemical parameters in peripheral blood from mice transplanted with sarcoma 180 tumour.

Table 3

Effect of propolis extracts on the hematological changes on peripheral blood.

\begin{tabular}{|c|c|c|c|c|c|c|c|c|}
\hline \multirow[t]{2}{*}{ Drug } & \multirow[t]{2}{*}{ Dose $\mathrm{mg} / \mathrm{kg}$} & \multirow[t]{2}{*}{ Hemoglobin (g/dl) } & \multirow[t]{2}{*}{ Platelets $\left(10^{6} \mathrm{cel} / \mu \mathrm{l}\right)$} & \multirow[t]{2}{*}{ Leukocytes $\left(10^{6} \mathrm{cel} / \mu \mathrm{l}\right)$} & \multicolumn{4}{|c|}{ Differential count (\%) } \\
\hline & & & & & Eosinophils & Neutrophils & Lymphocytes & Monocytes \\
\hline Salina & - & $12.26 \pm 0.31$ & $1240 \pm 119$ & $4.1 \pm 0.31$ & 0 & 44 & 36.00 & 8 \\
\hline 5-FU & 25 & $10.30 \pm 0.20$ & $934 \pm 54^{\mathrm{a}}$ & $1.2 \pm 0.21^{\mathrm{a}}$ & 0 & 52 & 37.00 & 7 \\
\hline \multirow[t]{2}{*}{ EEP70 } & 50 & $13.01 \pm 0.40$ & $1243 \pm 55$ & $3.96 \pm 0.40$ & 0.2 & 47 & 35.00 & 9 \\
\hline & 80 & $14.02 \pm 0.50$ & $1244 \pm 45$ & $3.87 \pm 0.30$ & 0.1 & 45 & 34.00 & 8 \\
\hline \multirow[t]{2}{*}{ ODEP } & 50 & $12.08 \pm 0.49$ & $1343 \pm 105$ & $3.12 \pm 0.34$ & 0 & 39 & 36.60 & 8 \\
\hline & 80 & $11.76 \pm 0.52$ & $1454 \pm 109$ & $4.15 \pm 1.22$ & 0 & 40 & 35.40 & 7 \\
\hline
\end{tabular}

Data are presented as mean \pm SEM.

a The differences between experimental groups were compared by ANOVA followed by Student Newman Keuls or Bonferroni tests ( $p<0.05$ ).

logical properties, propolis, which contains artepillin $C$ is considered as a high quality propolis and the content of artepillin $\mathrm{C}$ is already used in quality control by some companies (Funari \& Ferro, 2006). By visual inspections of the chromatograms (data not shown), from both LC-MS and LC-UV (PDA), it was evident that artepillin $\mathrm{C}$ is commonly present in propolis from Prudentópolis, and that the oil extracts of propolis do contain significant levels of prenylated phenolic acids, including artepillin C. Several other ions in the oily extract of propolis remained unknown indicating the need to carry on further studies of the chemical composition of this promising ODEP extract.

All treatment regimens for the majority of cancers produce side effects, which makes this treatment extremely unpleasant for patients. Scientists have spent therefore efforts to develop new therapies for the treatment of cancer. Propolis has been a subject of intense research, especially in the areas of anticancer research (Banskota et al., 2000; El-khawaga Om-Ali, Tarek, \& Mohammed, 2003; Padmavathi, Senthilnathan, Chodon, \& Sakthisekaran, 2006). The majority of those studies evaluated the ethanol, aqueous or methanol extracts of propolis, hence in this work we assessed the antitumour effect of an oil extract of propolis. We have previously reported data comparing antiproliferative activity against HL-60, MDAMB-435 and SF-295 cells lines of oil and ethanolic propolis extracts (Buriol et al., 2009). Because a different sample of propolis (but from the same region) and different conditions extractions were used, we can not directly compare the $\mathrm{IC}_{50}$ value reported earlier with the present values, but in both investigations the oil extracts of propolis were active against the tested tumour cell lines indicating more anticancer potential against the
SF-295 cell line than the ethanolic extracts. The present results show that the oil extract of propolis has substances with cytotoxic effects similar to the more common ethanolic extracts, making this extract attractive for applications where ethanol must be avoided. The oil extract of propolis also produced better inhibition of tumour cells than its fractions, indicating that propolis cytotoxic activity is probably a "shotgun" synergic effect of its many bioactive components. The biological activity of propolis should therefore be highly depended on the extraction process.

In the Sarcoma 180 model assay it was demonstrated that all propolis extracts inhibited tumour growth in mice with the same inhibition ratio as the positive control 5 -FU but with less side effects.

The histopathological analyses of organs removed from treated animals showed that the treatment with 5-FU, ODEP and EEP70 led to Kupffer cell hyperplasia and necrosis, which signals the presence of a toxic agent. Nevertheless, these alterations could be considered reversible (Kummar, Abbas, \& Fausto, 2004; Scheuer \& Lefkowitch, 2000).

Renal parameters were also evaluated. The histopathological analyses of the kidneys showed focal areas of necrosis in the tubular epithelium in all groups of treatment, suggesting that the treatment with 5-FU, ODEP and EEP70 caused kidney damage. Necrosis of the renal tubule epithelium may occur on a large scale as a consequence of the administration of different chemical classes (Olsen \& Solez, 1994). Although modifications of kidney tissues were observed, the analysis of biochemical parameters didn't show changes in levels of urea and creatinine. Nevertheless, blood urea was increased only a long time after renal alteration, which may 
explain why the treatment in this study failed to induce any alteration in the blood urea levels.

Separately from hepatotoxic and nephrotoxic effects, anticancer drugs also produce delayed hematopoietic depression, as observed in treatment with methotrexate and 5-FU (Bezerra et al., 2008; Katzung, 2003). In fact, most chemotherapeutic drugs, including 5-FU, are immunosuppressive because they kill many normal cells as well as tumour cells (Bezerra et al., 2008; Takiguchi et al., 2001) and have negative side effects. One of the risks of radiation and chemotherapy in the treatment of cancer patients is the development of leukopenia, which substantially increases the risk of infections. We observed herein leukopenia in the 5-FU treatment, but not in the EEP70 and ODEP treatment.

The weight of the spleens in animals treated with 5-FU was also significantly lower than in the control group, which also indicated an immunosuppressive side effect of 5-FU, but propolis treatment caused no alteration in the weight of the spleen. When comparing the histopathological analyses, we observed that all groups treated with propolis showed congestion on red pulp, which indicates a possible effect on the immodulatory system. It is well reported that the mechanism of antitumour effects elicited by propolis extracts has been attributed to its effect on the immodulatory system.

\section{Conclusions}

The findings in the present study indicate the potential of oil extract of propolis for the treatment of cancer. The ethanol-free vegetable oil extract of propolis displayed important in vitro and in vivo antitumour effects due to a synergic effect of its many bioactive constituents with moderate signs of toxicity.

\section{Acknowledgements}

We wish to thank Vassya S. Bankova, (Bulgarian Academy of Science) for the isosakuranetin standard. Financial support was provided by Finep and Fundação Araucária through 10908/PPP/ 2006 and 7102/PPI phase I-2004 and phase II-2006. DF and EMS wish to thank for a scholarship from CAPES and CSM thanks for a scholarship from Fundação Araucária. MNE and AFWS wish to thank FAPESP and CNPq for the financial support. The authors also thank Silvana França dos Santos and Erivanda França for their technical assistance. ACHFS thanks CAPES for a postdoctoral fellowship.

\section{References}

Banskota, A. H., Tezuka, Y., Prasain, J. K., Matsushige, K., Saiki, I., \& Kadota, S. (1998) Chemical constituents of Brazilian propolis and their cytotoxic activities. Journal of Natural Products, 61, 896-900.

Banskota, A. H., Tezuka, Y., Adnyana, I. K., Midorikawa, K., Matsushige, K., Message, M., et al. (2000). Biological evaluation of propolis from Brazil, Peru, the Netherlands and China. Journal of Ethnopharmacology, 72, 239-246.

Banskota, A. H., Tezuka, Y., \& Kadota, S. (2001). Recent progress in pharmacological research of propolis. Phytotherapy Research, 15, 561-571.

Bezerra, D. P., de Castro, F. O., Alves, A. P. N. N., Pessoa, C., de Moraes, M. O., Silveira, E. R., et al. (2008). In vitro and in vivo antitumor effect of 5-FU combined with piplartine and piperine. Journal of Applied Toxicology, 28, 156-163.

Burdok, G. A. (1998). Review of the biological properties and toxicity of bee propolis (Propolis). Food and Chemical Toxicology, 36, 347-363.
Buriol, L., Finger, D., Schmidt, E. M., Santos, J. M. T., Rosa, M. R., Quináia, S. P., et al. (2009). Composição química e atividade biológica de extrato oleoso de própolis: uma alternativa ao extrato etanólico. Química Nova, 32, 296-302.

Cuyckens, F., \& Claeys, M. (2004). Mass spectrometry in the structural analysis of flavonoids. Journal of Mass spectrometry, 39, 1-15.

El-khawaga Om-Ali, Y., Tarek, A. S., \& Mohammed, F. E. (2003). Protective role of Egyptian propolis against tumor in mice. Clinica Chimica Acta, 338, 11-16

Funari, C. S., \& Ferro, V. O. (2006). Análise de própolis. Ciência e Tecnologia de Alimentos, 26, 171-178.

Ghisalberti, E. L. (1979). Propolis a review. Bee World, 60, 59-84.

Gonzaga, M. L. C., Bezerra, D. P., Alves, A. P. N. N., Alencar, N. M. N., Mesquita, R. O., Lima, M. W., et al. (2009). In vivo growth-inhibition of Sarcoma 180 by an $\alpha$ $(1,4)$-glucan- $\beta-(1,6)$-glucan-protein complex polysaccharide obtained from Agaricus blazei Murill. Journal of Natural Medicine, 63, 32-40.

Kasuma, Y., \& Kenichi, I. (2001a). Propolis composition and its production. JP Pat. 20010374227 (A)

Kasuma, Y., \& Kenichi, I. (2001b). Extraction of propolis extract. JP Pat. 2001017096 (A).

Katzung, G. B. (2003). Basic and Clinical Pharmacology (9th ed.). USA: McGraw-Hill Medical.

Kummar, V., Abbas, A., \& Fausto, N. (2004). Robbins and Cotran pathologic basis of disease. China: W.B. Saunders.

Lustosa, S. R., Galindo, A. B., Nunes, L. C. C., Randau, K. P., \& Neto, P. J. R. (2008) Própolis: Atualizações sobre a química e farmacologia. Brazilian Journal of Pharmacognosy, 18, 447-454.

Marcucci, M. C. (1995). Propolis: Chemical composition, biological properties and therapeutic activity. Apidologie, 26, 83-99.

Marcucci, M. C., Sawaya, A. C. H. F., Custodio, A. R., Paulino, N., \& Eberlin, M. N. (2008). HPLC and ESI-MS typification: New approaches for natural therapy with Brazilian propolis. In N. Orsolic \& I. Basic (Eds.), Scientific evidence of the use of propolis in ethnomedicine (pp. 33-54). Kerala: Research Network.

Mosmann, T. (1983). Rapid colourimetric assay for cellular growth and survival: Application to proliferation and cytotoxicity assays. Journal of Immunological Methods, 65, 55-63.

Namiki, H., Matsuka, M., Nakamura, J., Adachi, S., Watanabe, G., Okazaki, M. Propolis extract and method for extracting the same. WO Pat. 2005/094853 (A1), 2005

Olsen, S., \& Solez, K. (1994). Acute tubular necrosis and toxic renal injury. In C. C. Tisher \& B. M. Brenner (Eds.), Renal pathology: with clinical and functional correlations (pp. 769-809). Philadelphia: JB. Lippincott Company.

Orsolic, N., \& Basic, I. (2003). Immunomodulation by water-soluble derivative of propolis: a factor of antitumor reactivity. Journal of Ethnopharmacology, 84, 265-273.

Padmavathi, R., Senthilnathan, P., Chodon, D., \& Sakthisekaran, D. (2006). Therapeutic effect of paclitaxel and propolis on lipid peroxidation and antioxidant system in 7,12 dimethyl benz(a)anthracene-induced breast cancer in female Sprague Dawley rats. Life Sciences, 78, 2820-2825.

Sawaya, A. C. H. F. Palma, A. M. Caetano, F. M. Marcucci, M. C Cunha, I. B. S. Araújo, C. E. P., et al. (2002). Comparative study of in vitro methods used to analyze the activity of propolis extracts with different compositions against species of Cândida. Letters in Applied Microbiology, 35, 203-207.

Sawaya, A. C. H. F., Tomazela, D. M., Cunha, I. B. S., Bankova, V. S., Marcucci, M. C., Custodio, A. R., et al. (2004). Electrospray ionization mass spectrometry fingerprinting of propolis. Analyst, 129, 739-744.

Sawaya, A. C. H. F., Souza, K. S., Marcucci, M. C., Cunha, I. B., \& Shimizu, M. T. (2004) Analysis of the composition of Brazilian propolis extracts by chromatography and evaluation of their in vitro activity against gram-positive bacteria. Brazilian Journal of Microbiology, 35, 104-109.

Sawaya, A. C. H. F., Cunha, I. B. S., Marcucci, M. C., Aidar, D. S., Silva, E. C. A., Carvalho, C. A. L., et al. (2007). Electrospray ionization mass spectrometry fingerprinting of propolis of native Brazilian stingless bees. Apidologie, 38, 93-103.

Shimizu, K., Ashida, H., Matsuura, Y., \& Kanazawa, K. (2004). Antioxidative bioavailability of artepillin $\mathrm{C}$ in Brazilian propolis. Archives of Biochemistry and Biophysics, 424, 181-188.

Scheuer, P. J., \& Lefkowitch, J. H. (2000). Drugs and toxins. In P. J. Scheuer \& J. H. Lefkowitch (Eds.), Liver biopsy interpretation (pp. 134-150). London: W.B. Saunders.

Takiguchi, N., Saito, N., Nunomura, M., Kouda, K., Oda, K., Furuyama, N., et al. (2001). Use of 5-FU plus hyperbaric oxygen for treating malignant tumors: evaluation of antitumor effect and measurement of 5-FU in individual organs. Cancer Chemotherapy and Pharmacology, 47, 11-14.

Tosi, B., Donini, A., Romagnoli, C., \& Bruni, A. (1996). Antimicrobial activity of some commercial extracts of propolis prepared with different solvents. Phytotherapy Research, 10, 335-336. 